\title{
Nitrate levels in drinking water and their impact on the risk of developing gynecological diseases and adverse pregnancy outcomes
}

\author{
Vasilios Pergialiotis, Dimitrios Loutradis
}

$1^{\text {st }}$ Department of Obstetrics and Gynecology, "Alexandra” Hospital, National and Kapodistrian University of Athens, Greece

Corresponding Author

$1^{\text {st }}$ Department of Obstetrics and Gynecology, National and Kapodistrian University of Athens, "Alexandra" Hospital, Athens, Greece, e-mail: asimakopoulos.geo5@gmail.com

\section{Abstract}

Nitrate is a nitrogen oxoanion formed by loss of a proton from nitric acid. It is an important source of nitrogen which is essential for protein formation. Regular levels of nitrate in the environment do not exceed 2-5 mg/L. Fertilizers, herbicides and pesticides increase, however, the amount of nitrate in drinking water. In 2011 the World Health Organization (WHO) has issued a revised document on nitrate and nitrite levels in drinking water to help establish a common guideline that will help countries. To date, the majority of guidelines on drinking water quality that is directly related to nitrate levels are based in its toxic effect in infants and neonates (primarily the occurrence of methemoglobinemia) and suggest as an arbitrary cutoff the existence of less than $10 \mathrm{mg} / \mathrm{L}$ as a measure of safety. Exposure to nitrate levels has been linked to adverse neurodevelopmental effects, fetal malformations and several forms of cancer. However, the associations remain scarce in several fields as the majority of available data is retrieved from articles that investigate the impact of nitrosatable drugs, rather than environmental exposure. In Greece, seven vulnerable regions have been recently identified, following the country`s referral to the Court of Justice by Commission. The aim of the present article is to summarize current evidence and provide recommendations for clinical practice and future research in the field.

Key words: Nitrate; gynaecology; obstetrics; adverse outcomes; fetal malformations; Greece

\section{Introduction}

Nitrogen is an essential component of proteins and is, therefore, mandatory for all living organisms on Earth. It is estimated that approximately $78 \%$ of the atmosphere consists of nitrogen, rendering it the largest source of nitrogen in the planet. In the environment it can be found in several forms and 
the nitrogen cycle regulates this process through the processes of fixation, ammonification, nitrification, and denitrification of nitrogen. In the soil, the primary source of nitrogen is considered to be decaying plants, residues of animals and various bacteria that transform nitrogen compounds in nitrate (NO3-). Besides these sources, various fertilizers and synthetic biochemical compounds that tend to pollute the environment increase nitrate levels. Therefore, territories inhabited by humans tend to have increased levels of nitrate.

Nitrate and nitrogen are undetectable without testing as they are colorless, tasteless and odorless. The World Health Organization (WHO) has issued a revised document on nitrate and nitrite levels in drinking water in 2011 to help establish a common guideline that will help countries form appropriate legislations for drinking water quality ${ }^{1}$. The importance of nitrate levels in public health is underlined by the first document that referred to the levels that should be considered as appropriate which was published by WHO in the first edition of Guidelines for Drinking Water Quality (GDWQ) in 1958 - shortly after the first reports of neonatal toxicity ${ }^{2}$. Human exposure to nitrate is more common through food and water consumption as air pollution is considered to be a minor source of nitrate exposure. The contribution of water and food on nitrate levels in humans is entirely dependent on the actual levels of nitrate in water. It is estimated that in areas with low levels of nitrate $(<10 \mathrm{mg} / \mathrm{l})$ the main source of nitrate are vegetables, which are commonly cultured with the use of pesticides, herbicides and fertilizers ${ }^{3-6}$. On the other hand, in areas where nitrate levels exceed 50 $\mathrm{mg} / \mathrm{l}$, drinking water may contribute to up to $14-20 \%$ of nitrate uptake in the average person ${ }^{1}$.

Considering the fact that neonates and infants that are bottle fed with formulas receive substantial levels of nitrate, it is estimated that in this population plain water is the major source of nitrate in their body. Extreme nitrate levels can directly and acutely harm neonates and infants by inducing methemoglobinemia, a life-threatening condition that leads to cyanosis, shortness of death, dizziness, headache, seizures, coma and even death ${ }^{7}$. The pathophysiological process that underlies this association is based in the reduction of nitrate to nitrite by bacteria that colonize the oral cavity of infants. Nitrite bounds to hemoglobin, forming methemoglobin which substantially reduces the oxygen carrying capacity of red blood cells, thus, depleting vital organs from oxygen. Methemoglobinemia is considered to be toxic when methemoglobin exceeds $10 \%$ of the normal hemoglobin concentration and it is believed that infants younger than 4 months are more prone to develop the condition as their system is immature and does not produce appropriate levels of nicotinamide adenine dinucleotide (NADH)-cytochrome b5-metHb reductase (an enzyme that is essential to help reduce methemoglobin to hemoglobin $)^{8}$.

To date, the majority of guidelines on drinking water quality that focus on nitrate levels is based in its toxic effect in infants and neonates. In 2000, Knobeloch et al reported two cases of methemoglobinemia in two infants that were bottle fed with well water with a concentration of nitrate-nitrogen of approximately $25 \mathrm{mg} / \mathrm{L}^{9}$. Studies in older children (aged 1-7 years) revealed that the methemoglobinemia did not occur until nitrate-nitrogen levels exceeded 50 $\mathrm{mg} / \mathrm{l}^{10}$. On the other hand, breastfeeding seems to be entirely protective against this condition as studies suggest that breasted children are not at risk, even when maternal consumption was high $(100 \mathrm{ppm}$ in drinking water) ${ }^{11}$. Taking in mind this information, the United States Environmental Protection Agency chose to issue a statement that suggests that the maximum contaminant level (MCL) for nitrate should be set at $10 \mathrm{mg} / \mathrm{L}$ (approximately one half of the lower levels observed in the international literature $)^{12}$.

Leaving aside the acute toxicity that nitrate-nitro- 
gen induces in neonates and infants, several reports have been published in the international literature during the last decades that underline the important adverse effects of nitrate on human physiology. The purpose of the present review is to summarize the associations of nitrate-nitrogen with gynecological diseases and adverse pregnancy outcomes, present information related to Greece and provide directions for current clinical practice and future research.

\section{Nitrate and infertility}

Current evidence does not support an association between nitrate consumption and the occurrence of infertility. However, the majority of data is retrieved from animal experimental studies, is relatively outdated and as stated in the WHO document lacks a standard multigenerational reproductive study protocol $^{1,13,14}$. On the other hand, indirect evidence has shown that nitric oxide is directly related with altered sperm parameters in men and with idiopathic infertility and endometriosis in women ${ }^{15,16}$. To date, it is known that nitric oxide is endogenously generated from the amino acid l-arginine following a process that is regulated by complex nitric oxide synthases. In 2010 Weitzberg et al proposed an alternative pathway of nitric oxide generation that is based in back reduction of nitrate and nitrite (which are generally considered to be inert end products $)^{17}$. Since then, however, there has been no study to support the potential interaction of nitrate consumption with infertility; hence, this remains to be investigated in forthcoming projects.

\section{Nitrate, antenatal healthcare}

\section{and adverse pregnancy outcomes}

The majority of available data in the field correlate nitrate to various fetal abnormalities that can be either lethal in utero, or result in pathophysiological and anatomical adverse effects later in life. Various reviews have focused in the past in this field and un- derline these consequences which seem to be more pronounced in populations that reside in locations with high environmental exposure ${ }^{18}$. A recent study that was conducted by Bose et al used Bayesian distributed lag interaction models to identify the potential window that renders lung function more sensitive in nitrate exposure and revealed that early gestational exposure reduces lung capacity at 7 years of age ${ }^{19}$. Consequently, this results in increased risk of asthma occurrence ${ }^{20}$, whereas, exposure in early childhood seems to be also associated with the development of eczema (atopic dermatitis) ${ }^{21}$.

Neonates exposed in high nitrate levels in utero exhibit thyroid abnormalities as well also and the underlying pathophysiological routes that have been speculated rely on the reduced thyroid absorption of iodine. Specifically, nitrate seems to inhibit the sodium/iodine symporter as the latter seems to be responsible for the transportation of iodide, thiocynate, nitrate and perchlorate ${ }^{22}$. This is why speculations related to the potential harmful effect of these substances on fetal neurodevelopment have been previously communicated ${ }^{23}$. In the clinical setting, nitrate is not considered to be a potent goitrogenic substance; however, several reports indicate that it may induce mental retardation through suppressed thyroid function ${ }^{24}$. Various reports have been published in this field with conflicting results and a recent study from the Isfahan province which recruited women with moderate exposure to nitrate (10-36 $\mathrm{mg} / \mathrm{L}$ ) did not reveal a significant association between nitrate levels and congenital hypothyroidism ${ }^{25}$.

The sodium iodine symporter that was previously mentioned has been also considered as a potential mechanism that could correlate nitrate exposure to neonatal size and gestational age at delivery ${ }^{26}$. Evidence is, nevertheless, extremely scarce in the literature and does not support this association. Specifically, a recent study that included 107 pregnant women did not reveal significant differences in the 
anthropometric indices of fetuses ${ }^{27}$.

Neural tube defects have been also reported among women that consume nitrosatable drugs and the relative increase of these disorders has been reported to reach 2.7 (95\% confidence interval [CI] = 1.4-5.3) compared to the unexposed population ${ }^{28}$. In 2011 the National Birth Defects Prevention Study that involved 1,223 case mothers with neural tube defect-affected pregnancies and 6,807 control mothers confirmed this association ${ }^{29}$. Environmental exposure through the consumption of water nitrates does not seem to be, however, as significant as anticipated ${ }^{30,31}$.

Nitrosatable drug exposure has been also linked to hypoplastic left heart syndrome, limb deficiencies and oral clefts ${ }^{32}$. Prenatal vitamin C supplementation may help reduce the incidence of these malformations and is suggested by the National Birth Defects Prevention Study group ${ }^{33}$. However, as in the case of neural tube defects, environmental exposure from drinking water and vegetables has not been linked, yet, to these complications.

Despite the significant amount of data that seem to correlate nitrate to adverse pregnancy pregnancy outcomes, there is also indirect evidence that supports the use of antenatal nitrate supplementation in fetal growth restriction and preeclampsia. The assumption of this beneficial effect is based in the observation of low nitrate/nitrite levels in plasma and urine samples of patients with preeclampsia ${ }^{34}$, The potential beneficial effect of nitrate is thought to be exerted through its reduction to nitrite and nitric oxide which seems to improve the impaired uteroplacental vascular function that is observed among pregnancies complicated by FGR and hypertensive disorders of pregnancy ${ }^{35}$. Nevertheless, the actual level of human exposure to nitrate has not been sufficiently reported among these pregnancies; hence, several gaps exist in the literature that require further investigation. Moreover, the small sample size that has been used renders impossible the communication of potential adverse effects on fetal development, as these require large sample sizes that usually can be retrieved by population based studies.

A significant issue that needs to be determined among studies investigating the potential effect of nitrate on antenatal outcomes of fetuses is the actual exposure of the fetus, which is mostly based on maternal exposure levels. In 2006 Blount et al suggested that ion chromatography and electrospray tandem mass spectrometry are useful in determining accurately perchlorate, thiocyanate, nitrate and iodide in human amniotic fluid ${ }^{36}$. This measurement is of course not feasible in the clinical setting as a screening tools as it would require the implementation of prenatal amniocentesis in nearly all cases. However, calibration of the actual correlation of maternal serum and amniotic fluid levels could be feasible in high risk populations in order to help establish a common minimally invasive measurement (based in peripheral blood sampling) that accurately reflects the level of neonatal exposure following maternal consumption of increased doses of nitrate.

\section{Nitrate and gynaecological cancer}

The National Cancer Institute has published a statement in 2019 that correlates increased nitrate consumption with an increased risk of developing colon, kidney, and stomach cancer ${ }^{37}$. In 2001 the Iowa Women's Health Study was the first population based study that revealed that municipal drinking water nitrate level was directly linked to cancer risk in older women ${ }^{38}$. In a recent meta-analysis, Xie et al observed that nitrate levels are positively associated with adult glioma and thyroid cancer risk with pooled RR of $1.21(95 \% \mathrm{CI}=1.03-1.42)$ and $1.52(95 \% \mathrm{CI}=$ $1.12-2.05)^{39}$. Information in the field of gynaecological cancer, including breast cancer, is scarce; however, the aforementioned meta-analysis combined data from 3 published studies in the field of breast cancer and 
revealed that the relative risk does not increase $((\mathrm{RR}=$ $0.97,95 \% \mathrm{CI}=0.79-1.19)$. Nevertheless, the findings of this study are limited by the aggregated nature of the data that were used which precludes the feasibility of appropriate subgroup analyses using different cut-off values for abnormal nitrate exposure. The National Institutes of Health (NIH)-AARP Diet and Health Study provides more robust information that supports an association between nitrate and nitrite and ovarian cancer risk ${ }^{40}$. For the purposes of this latter study, 151,000 women were investigated and those belonging to the highest intake category of animal sources of nitrite were found to have a $34 \%$ increased risk (95\% CI: 1.05-1.69) of developing ovarian cancer. The same conclusions were also provided by Choi et al who also observed that private well users were more likely to develop ovarian cancer $(\mathrm{HR}=1.53$, $\mathrm{CI}=0.93-2.54)^{41}$. To date, there are no studies in the field of other forms of gynecological cancer and it is the authors ' belief that future research should at least target the potential interplay of nitrate/nitrate with endometrial pathology.

\section{Discussion}

Several factors seem to regulate nitrate exposure, including geological, agricultural and seasonal influences. Groundwater is distinguished at 2 subsurface levels, shallow and deep, using an arbitrary limit of 5 meters. It is estimated that shallow groundwater is more susceptible to environmental pollutants including chemical and nitrogenous fertilizers. In the United States the majority of the population has access to drinking water from domestic wells and major aquifers ${ }^{42}$. Nevertheless, a significant proportion of families still receives water from private wells and in the U.S. this is estimated to reach $14 \%$ of the population ${ }^{43}$. The actual MCL of nitrate in these wells cannot be estimated; however, previous studies suggest that in more than $20 \%$ of cases these exceed the appropriate $\mathrm{MCL}^{44}$. It is, therefore, anticipated that approximately $3 \%$ of the population is exposed to abnormal nitrate levels which can be toxic in the long term. This is why the American Academy of Pediatrics recommends that all prenatal and wellinfant visits should include questions that address information concerning the water home supply ${ }^{45}$.

In Greece, the issue of nitrate exposure is relatively unexplored and in 2019 the European Commission decided to refer Greece to the Court of Justice asking for financial sanctions ${ }^{46}$. The reason behind this decision is Greece`s reluctance to provide information on Nitrate Vulnarable Zones and absence of a national policy concerning the establishment of specific action programs for these areas. Recently, the Ministry of Environment and Energy has designated seven vulneralble zones (Figure 1) according to the requirements of the Directive 91/676/ EEC (transposed into national legislation with JMD

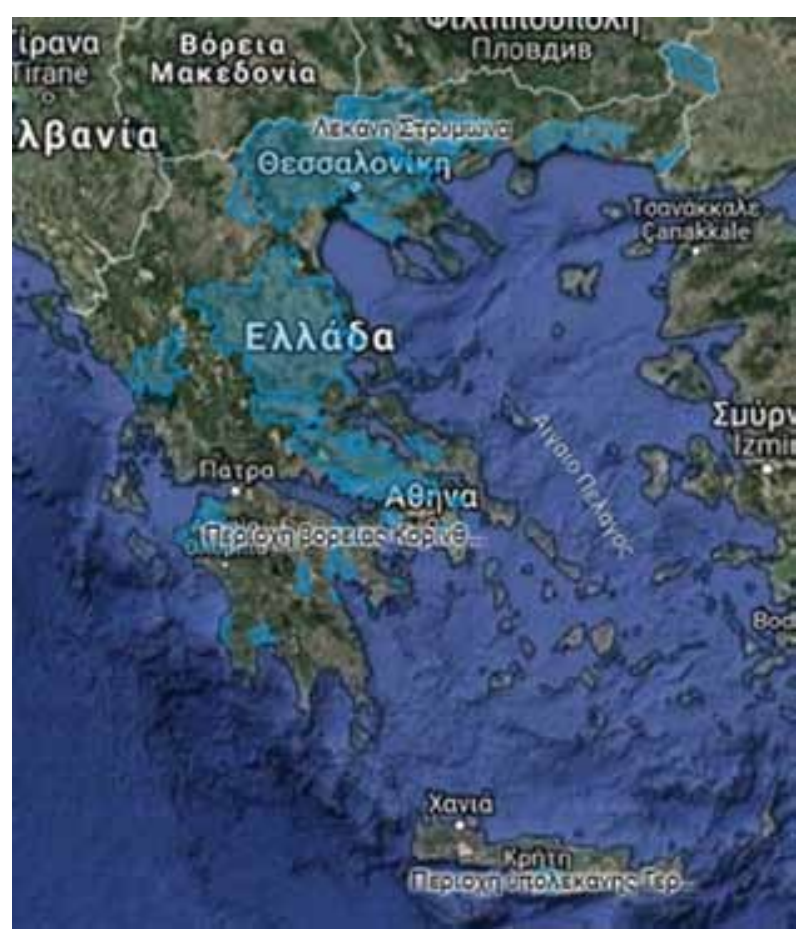

Figure 1. Vulnerable zones in Greece (highlighted in blue). 
$161890 / 1335 / 1997)^{47}$ and underlined the necessity for the adoption of sound agricultural practices that will limit the level of exposure of the population at risk. The actual cut-off level for safety is not transparently reported; however, the statement refers to the level of $25 \mathrm{mg} / \mathrm{L}$ as an endpoint above which nitrate exposure should be considered as a matter of public health concern.

Implications for current clinical practice and future research in the field

Given the information presented in the present article, physicians in Greece should address the issue of the safety of the available drinking water during patient assessment. Ideally, this should be done in the first prenatal visit and during the first pediatric assessment of newborns. Specific programs should target populations at risk and evaluate the amount of nitrate exposure and correlate this to the reported adverse effects that are presented by ELSTAT (the Hellenic Statistical Authority). This way we will be able to retrieve more information concerning the actual correlation of nitrate with gynaecological diseases and adverse pregnancy outcomes in the Greek population that will help establish a national preventive plan and diminish the potential adverse effects that arise from abnormal environmental exposure.

\section{References}

1. Chemical hazards in drinking-water: Nitrate and nitrite. Nitrate and nitrite are considered in the WHO Guidelines for Drinking-water Quality (GDWQ). https://www.who.int/water_sanitation_health/water-quality/guidelines/chemicals/nitratesnitrite/en/. Retrieved November 27th 2019.

2. Comly HH. Landmark article Sept 8, 1945: Cyanosis in infants caused by nitrates in well-water. By Hunter H. Comly. Jama 1987;257(20):2788-92.

3. Ueno E, Oshima H, Saito I, Matsumoto H. Deter- mination of nitrogen- and phosphorus-containing pesticide residues in vegetables by gas chromatography with nitrogen-phosphorus and flame photometric detection after gel permeation chromatography and a two-step minicolumn cleanup. J AOAC Int 2003;86(6):1241-51.

4. Potera C. Agriculture: pesticides disrupt nitrogen fixation. Environmental health perspectives 2007;115(12):A579-A.

5. Elias D, Bernot MJ. Pesticide and nitrate transport in an agriculturally influenced stream in Indiana. Environ Monit Assess 2017;189(4):162.

6. Liu C-W, Sung Y, Chen B-C, Lai H-Y. Effects of nitrogen fertilizers on the growth and nitrate content of lettuce (Lactuca sativa L.). International journal of environmental research and public health 2014;11(4):4427-40.

7. Ludlow JT, Wilkerson RG, Nappe TM. Methemoglobinemia. [Updated 2019 Jun 11]. In: StatPearls [Internet]. Treasure Island (FL): StatPearls Publishing; 2019 Jan-. Available from: https://www. ncbi.nlm.nih.gov/books/NBK537317/.

8. Maran J, Guan Y, Ou C-N, Prchal JT. Heterogeneity of Molecular Biology of Methemoglobinemia; Study of Eight Consecutive Patients. Blood 2004;104(11):1587-.

9. Knobeloch L, Salna B, Hogan A, Postle J, Anderson H. Blue babies and nitrate-contaminated well water. Environ Health Perspect 2000;108(7):675-8.

10. Sadeq M, Moe CL, Attarassi B, Cherkaoui I, Elaouad $\mathrm{R}$, Idrissi L. Drinking water nitrate and prevalence of methemoglobinemia among infants and children aged 1-7 years in Moroccan areas. Int J Hyg Environ Health 2008;211(5-6):546-54.

11. Greer FR, Shannon M. Infant methemoglobinemia: the role of dietary nitrate in food and water. Pediatrics 2005;116(3):784-6.

12. United States Environmental Protection Agency. Ground Water and Drinking Water. National Primary Drinking Water Regulations. https://www. 
epa.gov/ground-water-and-drinking-water/ national-primary-drinking-water-regulations.

13. Olsen P, Gry J, Knudsen I, Meyer O, Poulsen E. Animal feeding study with nitrite-treated meat. IARC Sci Publ 1984(57):667-75.

14. Vorhees CV, Butcher RE, Brunner RL, Wootten V. Developmental toxicity and psychotoxicity of sodium nitrite in rats. Food Chem Toxicol 1984;22(1):1-6.

15. Buzadzic B, Vucetic M, Jankovic A, et al. New insights into male (in)fertility: the importance of NO. British journal of pharmacology 2015;172(6):1455-67.

16. Dong $M$, Shi $Y$, Cheng $Q$, Hao M. Increased nitric oxide in peritoneal fluid from women with idiopathic infertility and endometriosis. J Reprod Med 2001;46(10):887-91.

17. Weitzberg E, Hezel M, Lundberg JO. Nitrate-nitrite-nitric oxide pathway: implications for anesthesiology and intensive care. Anesthesiology 2010;113(6):1460-75.

18. Ahmed M, Rauf M, Mukhtar Z, Saeed NA. Excessive use of nitrogenous fertilizers: an unawareness causing serious threats to environment and human health. Environ Sci Pollut Res Int 2017;24(35):26983-7.

19. Bose S, Rosa MJ, Mathilda Chiu YH, et al. Prenatal nitrate air pollution exposure and reduced child lung function: Timing and fetal sex effects. Environ Res 2018;167:591-7.

20. Bose S, Chiu YM, Hsu HL, et al. Prenatal Nitrate Exposure and Childhood Asthma. Influence of Maternal Prenatal Stress and Fetal Sex. Am J Respir Crit Care Med 2017;196(11):1396-403.

21. Kathuria P, Silverberg JI. Association of pollution and climate with atopic eczema in US children. Pediatr Allergy Immunol 2016;27(5):478-85.

22. Portulano C, Paroder-Belenitsky M, Carrasco N. The Na+/I- symporter (NIS): mechanism and medical impact. Endocr Rev 2014;35(1):106-49.
23. Knight BA, Shields BM, He X, et al. Effect of perchlorate and thiocyanate exposure on thyroid function of pregnant women from South-West England: a cohort study. Thyroid Res 2018;11:9.

24. Office of Environmental Health Hazard Assessment. Public Health Goals for Nitrate and Nitrite in Drinking Water; 1997. [Last cited on $2011 \mathrm{Feb}$ 20]. Available from: http://www.oehha.ca.gov/ water/phg/pdf/nit2_c.pdf .

25. Mehrnejat N, Yazdanpanah H, Fadaei Nobari R, et al. Spatial Analysis of Neonatal Congenital Hypothyroidism and Nitrate as an Environmental Pollutant in Isfahan Province During 2010-2013. International journal of preventive medicine 2015;6:76-.

26. Migeot V, Albouy-Llaty M, Carles C, et al. Drinkingwater exposure to a mixture of nitrate and lowdose atrazine metabolites and small-for-gestational age (SGA) babies: a historic cohort study. Environ Res 2013;122:58-64.

27. Evans KA, Rich DQ, Weinberger B, et al. Association of prenatal perchlorate, thiocyanate, and nitrate exposure with neonatal size and gestational age. Reprod Toxicol 2015;57:183-9.

28. Brender JD, Olive JM, Felkner M, Suarez L, Marckwardt W, Hendricks KA. Dietary nitrites and nitrates, nitrosatable drugs, and neural tube defects. Epidemiology 2004;15(3):330-6.

29. Brender JD, Werler MM, Kelley KE, et al. Nitrosatable drug exposure during early pregnancy and neural tube defects in offspring: National Birth Defects Prevention Study. American journal of epidemiology 2011;174(11):1286-95.

30. Arbuckle TE, Sherman GJ, Corey PN, Walters D, Lo B. Water nitrates and CNS birth defects: a population-based case-control study. Arch Environ Health 1988;43(2):162-7.

31. Croen LA, Todoroff K, Shaw GM. Maternal Exposure to Nitrate from Drinking Water and Diet and Risk for Neural Tube Defects. American Journal of 
Epidemiology 2001;153(4):325-31.

32. Brender JD, Werler MM, Shinde MU, et al. Nitrosatable drug exposure during the first trimester of pregnancy and selected congenital malformations. Birth Defects Res A Clin Mol Teratol 2012;94(9):701-13.

33. Shinde MU, Vuong AM, Brender JD, et al. Prenatal exposure to nitrosatable drugs, vitamin $\mathrm{C}$, and risk of selected birth defects. Birth Defects Res A Clin Mol Teratol 2013;97(8):515-31.

34. Schiessl B, Strasburger C, Bidlingmaier M, et al. Plasma- and urine concentrations of nitrite/nitrate and cyclic Guanosinemonophosphate in intrauterine growth restricted and preeclamptic pregnancies. Arch Gynecol Obstet 2006;274(3):150-4.

35. Cottrell E, Tropea T, Ormesher L, et al. Dietary interventions for fetal growth restriction - therapeutic potential of dietary nitrate supplementation in pregnancy. J Physiol 2017;595(15):5095-102.

36. Blount BC, Valentin-Blasini L. Analysis of perchlorate, thiocyanate, nitrate and iodide in human amniotic fluid using ion chromatography and electrospray tandem mass spectrometry. Anal Chim Acta 2006;567(1):87-93.

37. National Cancer Institute: Cancer Trends Progress Report. Online Summary of Trends in US Cancer Control Measures - Nitrate. https://progressreport.cancer.gov/prevention/nitrate.

38. Weyer PJ, Cerhan JR, Kross BC, et al. Municipal drinking water nitrate level and cancer risk in older women: the Iowa Women's Health Study. Epidemiology 2001;12(3):327-38.

39. Xie L, Mo M, Jia H-X, Liang F, Yuan J, Zhu J. Association between dietary nitrate and nitrite intake and sitespecific cancer risk: evidence from observa- tional studies. Oncotarget 2016;7(35):56915-32.

40. Aschebrook-Kilfoy B, Ward MH, Gierach GL, et al. Epithelial ovarian cancer and exposure to dietary nitrate and nitrite in the NIH-AARP Diet and Health Study. Eur J Cancer Prev 2012;21(1):65-72.

41. Inoue-Choi M, Jones RR, Anderson KE, et al. Nitrate and nitrite ingestion and risk of ovarian cancer among postmenopausal women in Iowa. Int J Cancer 2015;137(1):173-82.

42. Richard AM, Diaz JH, Kaye AD. Reexamining the risks of drinking-water nitrates on public health. The Ochsner journal 2014;14(3):392-8.

43. Maupin, M.A.; Kenny, J.F.; Hutson, S.S.; Lovelace, J.K.; Barber, N.L.; Linsey, K.S. Estimated Use of Water in the United States in 2010; US Geological Survey: Reston, VA, USA, 2014; p. 56.

44. U.S. Geological Survey. USGSWater Data for the Nation. Available online: https://waterdata.usgs. gov/nwis. (accessed on Nomber 30th 2018).

45. ATSDR Case Studies in Environmental Medicine Nitrate/Nitrite Toxicity. Agency for Toxic Substances and Disease Registry. .

46. Press release: 7 March 2019. Nitrates: Commission decides to refer Greece to the Court of Justice and asks for financial sanctions. https:// ec.europa.eu/commission/presscorner/detail/ en/IP_19_1482.

47. Ministry of Environment and Chemistry: Nitrate Pollution. http://www.ypeka.gr/Default. aspx?tabid $=250 \&$ locale $=$ en - US\&language $=e l-G R$.

Received 20-11-2019

Revised 25-11-2019

Accepted 28-11-2019 